\title{
Pulsed electric fields (PEF) applications on wine production: A review
}

\author{
Burcu Ozturk ${ }^{1, \mathrm{a}}$ and Ertan Anli ${ }^{2, \mathrm{~b}}$ \\ ${ }^{1}$ Namık Kemal University Şarköy Vocational School, Wine Production Technology Programme, 59800 Şarköy- Tekirdağ, Turkey \\ ${ }^{2}$ Ankara University Engineering Faculty, Food Engineering Department, 06110 Dışkapı-Ankara, Turkey
}

\begin{abstract}
Novel techniques have been searched in the last decades as a result of increasing demand for high quality food products. Non-thermal processing technologies, such as pulsed electric fields (PEF) have been improved to achieve inhibition of deleterious effects on quality-related compounds. The working principle of PEF is based on the application of pulses of high voltage (typically above $20 \mathrm{kV} / \mathrm{cm}$ up to $70 \mathrm{kV} / \mathrm{cm}$ ) to liquid foods placed between two electrodes. Pulsed electric fields technique has also been studied in winemaking process. Certain positive influences of PEF on vinification have been reported as elimination of pathogenic microorganisms, reduction of maceration time, increase in phenolic compounds extraction , acceleration of wine aging and inactivation of oxidative enzymes. The aim of this review is to summarize the potential applications of PEF in winemaking and to express its effects on quality of wine.
\end{abstract}

\section{Introduction}

Non-thermal techniques have been researched widespread aiming at maintaining food qulity. Pulsed electrical fields (PEF) as an alternative to conventional techniques is an innovative process offering improvement of food quality by reducing the cost of energy [1-3]. The PEF technology has various advantages like shorter processing time, lower treatment temperature, and continuous flow when compared with conventional thermal processes [2]. It suggests increase in production efficiency and low processing temperature diminishes the food quality deterioration risk [1].

Winemaking techniques play a crucial role in terms of wine quality and aging stabilitiy of wine. Among them extraction of phenolic compounds has the most powerful effect on both organoleptic quality and stability of wine. On the other hand inactivation of spoilage microorganisms is of crucial significance in order to control the deterioration of wine and reduce the economical losses of wine producers.

Electroporation, which causes increase in the cell membrane permability and conductivity, is a phase that is originated by means of externally applied electric field of adequate strength $[3,4]$. The electroporation resulted from PEF treatments has indicated effective results for extraction of juice, and other important compounds from grape tissue, nonthermal preservation by microbial inactivation and increasing fermentation activity of yeasts $[5,6]$.

This review is focused on main points of PEF technique, various applications on different wine production stages and the changes in certain wine quality parameters related to these applications.

\footnotetext{
a e-mail: bozturk@nku.edu.tr

b e-mail: anli@eng. ankara.edu.tr
}

\section{PEF mechanism}

PEF is a novel technology which includes the application of microsecond $(\mu \mathrm{s})$ pulses of high electric field to a material placed between two electrodes [7]. A classical systems for the treatment of pumpable fluids composed of a PEF generation unit that consists of a high voltage generator and a pulse generator respectively, a treatment chamber, a proper product process system and a set of monitoring and controlling equipment $[7,8]$ (Fig. 1).

With the help of energy transfer to the fluid PEF treatments cause an increase in temperature and electrical conductivity of the treatment medium. The temperature increase changes viscosity and stability of the cell membrane and changed conductivity at constant energy input diminishes the field strength [9].

\section{Electroporation strategy}

The first step of PEF treatment is electroporation, also named as electropermeabilization, is electrical breakdown of cell membranes via externally applied electrical field of adequate strength yields a raise in cell's plasma membrane conductivity and permeability [4]. This ability of the treatment is utilised for killing microorganisms [8]. Membrane electroporation property has found different field of application to improve other new processes via induction of mechanical, hydrodynamic, osmotic viscoelastic instabilities progressively [10].

There are three possible results of PEF associated with the duration of cell exposure, the local field strength (maximum amount of enery givable to the membrane via external electrical field), and the rate of membrane recovery. When the field strength and exposure time are inadequate, there is no electroporation and no change 




Figure 1. Schematics of a PEF processing system for pumpable products [7].

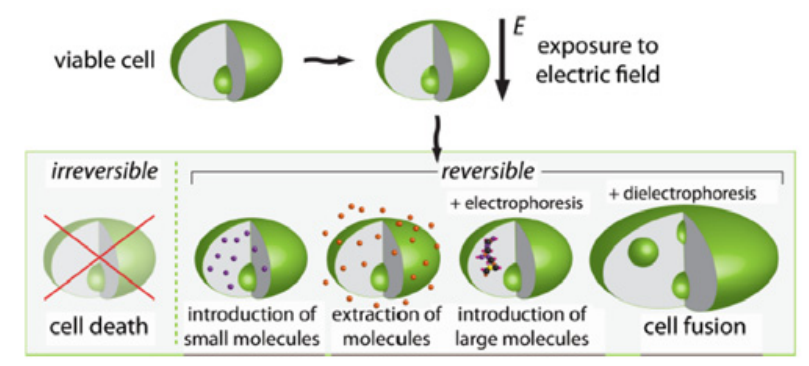

Figure 2. The schematic illustration of possible outcomes of cell electroporation depending on the pulsing dynamic (amplitude, shape, duration of pulses) and extra cell distotion technique (dielectrophoresis) [4,11].

in cell's viability and permeability. If the field strength goes over the reversable threshold and exposure period is adequate, reversible electroporation takes place (Fig. 2). In other words the membrane permeabilized for a period of time and can turn to its original state thanks to membrane resealing. Irreversible electroporation, which results in loss of cell homoestosis and death of the cell, only occurs providing that the field strength and amount of delivered energy are excessive [4,11-13].

\section{Applications on wine microbiota}

The control of spoilage microorganisms like the yeasts of genus Dekkera/Brettanomyce/Candida and the lactic acid bacteria of genus Lactobacillus in must, wine and wine contact surfaces is of vital importance for winemakers $[9,14]$. Thermal treatments, addition of preservatives like sulferdioxide $\left(\mathrm{SO}_{2}\right)$, ascorbic acid, sorbic acid and dimetyhl dicarbonate and microfiltration are the most common techniques tried to control or prevent microbial growth $[15,16]$.

As an alternative to the common method of $\mathrm{SO}_{2}$ usage $\mathrm{PEF}$ is searched to control and inhibit microbial growth. The effect of PEF or high voltage electrical discharge (HVED) was compared for the control of sweet white must fermentation with $\mathrm{SO}_{2}$ addition by Delsart et al [17]. As a result the inactivation of total yeasts and nonSaccharomyces yeasts was achieved with the influence of PEF (from $4 \mathrm{kV}^{*} \mathrm{~cm}^{-1}$ to $20 \mathrm{kV}^{*} \mathrm{~cm}^{-1}$; from $0,25 \mathrm{~ms}$ to $6 \mathrm{~ms})$ and HVED $(40 \mathrm{kV} / \mathrm{cm} ; 1 \mathrm{~ms}$ or $4 \mathrm{~ms})$. They reported
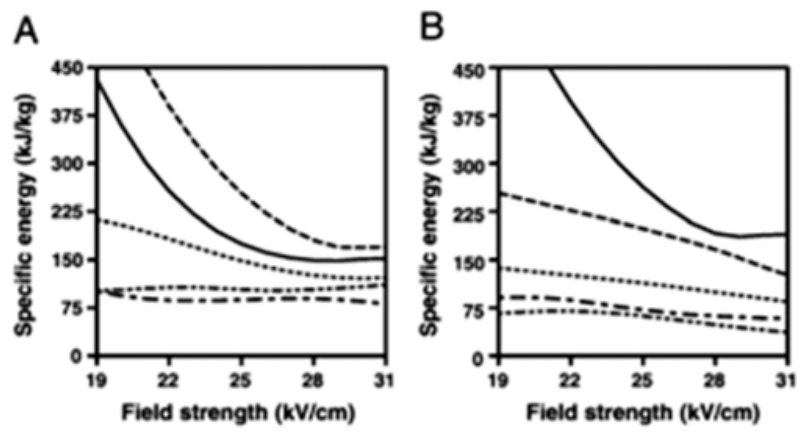

Figure 3. Treatment conditions, field strength and specific enery to achieve $3 \log$ cycles of inactivation in must (A) or wine (B) of red grape, of the different studied microorganisms $D$. anomala (... ), D. bruxellensis (-. -.),S. bayanus (-. - -),L. plantarum (-), L. hilgardii (-) [14].

that the highest inactivation rate with PEF treatment was obtained at $\mathrm{E}=20 \mathrm{kV} / \mathrm{cm}, \mathrm{t}_{\mathrm{PEF}}=4 \mathrm{~ms}, \mathrm{~W}=320 \mathrm{~kJ} * \mathrm{~L}^{-1}$. In addition PEF technology was found more proper for sweet wines than HVED hence it caused no browning problem [17].

Puértolas et al. investigated the lethal effect of PEF on different spoilage microorganisms (Dekkeral Brettanomycess and Lactobacillus) in must and wine. The effect of electrical field strength and the specific energy on inactivation of various microorganisms is illustrated in Fig. 4. The microbial death rate was observed greater during the first period of processing and a progressive decrease was recognised which is referred to as 'tailing behaviour'. Lactic acid bacteria were found more PEF resistant than yeast whichwas explained by their larger size since less intensive field strengths was required to electroporate their cell membranes. Among all microbial species $L$. plantarum was found the most PEF resistant in wine and L. hilgardii in must [14]. The higher PEF resistance in wine of $L$. plantarum was related to its high resistance to environmental conditions at raised ethanol concentrations [18].

The efficiency of PEF treatment is reported to be relevant to the temperature since microbial sensitivity rises with temperature [19]. The size, shape, morphological and biochemical features of the cells are incharge of cell resistance to PEF conditions. In addition, other physicochemical factors like $\mathrm{pH}$, alcohol content, water activity, solible solids, electrical conductivity or temperature should also be kept in mind according to sensitivity of the microorganisms [20-23].

PEF technology was also investigated as to the its stimulating effect on microbial flora. It is reported by Mattar et al. (2015) that electroporation was exposed by the advancement of fermentation activity in this way raised yeast metabolism [24]. In accordance with stress response analysis of $S$. cerevisiae, PEF induced expression of the oxidation genes and glutathione played a crucial role in the stres resistance [25]. According to the results of the study performed by Mattar et al. (2015), it is proved that PEF has stimulating influence on synthesis of RNA and ezymes, frequency of cell division events, tolerance to ethanol and fermentation capacity [24]. 

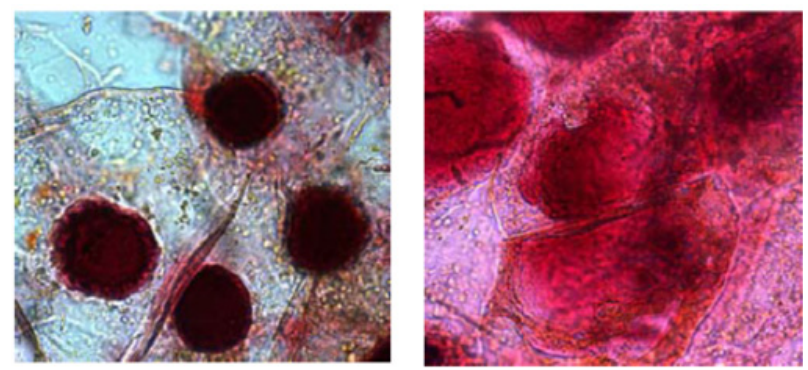

Figure 4. Microscopic photos of peel tissue of Lemberger wine grapes before and after electroporation [29].

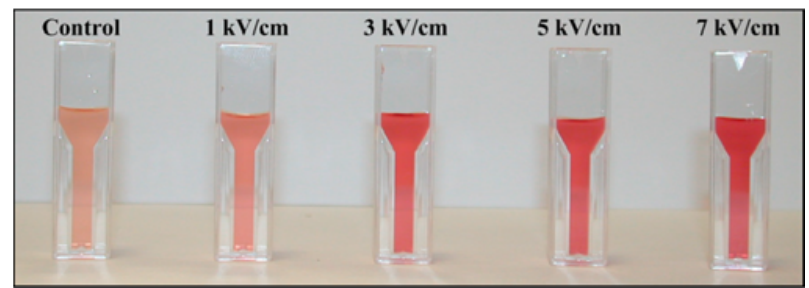

Figure 5. Image of the Garnacha must after $1 \mathrm{~h}$ of maceration with grapes untreated and treated by PEF (50 exponential decay pulses; $1-7 \mathrm{kV} / \mathrm{cm} ; 0,4-4,1 \mathrm{~kJ} / \mathrm{kg}$ ) [20].

\section{Applications for improvement of oenological characteristics}

The extraction of precious substances such as flavouring substances or pigments from wine grapes is of crucial for the wine production industry [26]. The phenolic compounds supply significant organoleptic properties of red wines like colour, bitterness, astringency and mouthfeel. Furthermore via their antimicrobial and antioxidant capacity phenolic substances make essential contribution to aging capacity [27,28]. An adequate extraction is provided by perforating the cells of berry tissue. The novel technique PEF causes formation of pores in the cell membrane via electroporation $[29,30]$. As illustrated in Fig. 4 after the electric field treatment, cell membrane is charged which causes opening the membranes and vacuoles.

Corrales et al. (2008) reported that the application of PEF treatment $(3 \mathrm{kV} / \mathrm{cm}, 30$ pulses, $10 \mathrm{~kJ} / \mathrm{kg})$ to the grape skins improved the total phenolic content and anthocyanins in the extraction medium $100 \%$ and $17 \%$ respectively, compared to the untreated ones [31]. In another study it was proved that phenolic concentration in the extraction medium of Chardonnay grape was doubled after treatment of $1000 \mu \mathrm{s}$ duration at $1,3 \mathrm{kV} / \mathrm{cm}$ for $1 \mathrm{~s}$ [32].

The influences of PEF treatment on accelaration and increase of phenolic extraction from grape skins in the course of maceration and fermantation process have been researced extensively. In accordance with the previous studies $[3,14,20]$ performed with a cylindirical batch paralel electrode treatment chamber, with a distance between the electrodes of $1 \mathrm{~cm}$ and area of $19,64 \mathrm{~cm}^{2}$, it has proved that PEF technique enhanced the colour of must in maceration step (Fig. 5).

Effect of PEF treatment during cold maceration and alcoholic fermentation on oenological characteristics of Cabernet Sauvignon red wines have been searched. Moderate and high field strengths $(\mathrm{E}=0,8 \mathrm{kV} / \mathrm{cm}$ and $5 \mathrm{kV} / \mathrm{cm}$ ) were applied prior and during alcoholic fermentation on red grapes on enhancement of different parameters. The application of PEF utilising moderate strength at different times in the course of cold maceration (0,2, and 4 days) was found more effective during the cold maceration treatment. It was proved that PEF induce membrane electropermeabilization, improving phenolic compounds extraction during cold maceration and raising the resultant colour index [33].

\section{Conclusion}

In this review, it has been emphasised the innovative technique PEF can be an efficient treatment to improve important onelogical characteristics of wine and to inhibit spoilage microosganisms [20]. In general PEF cause low temperature increase that prevents heat-induced changes in colour, flavour, taste, and nutrient content of food $[9,34]$. $\mathrm{PEF}$ gives rise to local structural changes of cell membrane and degenaration of membrane permeability barrier by means of electroporation. Thus PEF pretreatment can be a promising alternative on microbial inhibition of wine wine without any browning problem. On the other hand the efficiency of the technique is reported to be improved with the utilisation of other electrical pulse shapes, pressurized or degassed wine to avoid electrical discharge problem in gas bubbles and the combination of other technologies with PEF [17].

\section{References}

[1] N. Yang, K. Huang, C. Lyu, J. Wang. Pulsed electric field technology in the manufacturing processes of wine, beer, and rice wine: A review. Food Control 61, 28-38 (2016)

[2] E. Puértolas, N. López, S. Condón, I. Alvarez, and J. Raso J. Potential applications of PEF to improve red wine quality. Trends in Food Science \& Technology 21, 247-255 (2010)

[3] N. López, E. Puértolas, and S. Condon. Application of pulsed electric fields for improving the maceration process during vinification of red wine: influence of grape variety. Eur Food Res Technol. 227, 10991107 (2008)

[4] S. Mahnič-Kalamiza, E. Vorobiev, and D. Miklavčič. Electroporation in food Processing and Biorefinery. J. Membrane Biol. 247, 1279-1304 (2014)

[5] I. Odriozola-Serrano, I. Aguilo-Aguayo, R. SolivaFortuny, and O. Martın-Belloso. Pulsed electric fields processing effects on quality and health-related constituents of plant-based foods. Trends in Food Science\&Technology 29, 98-107 (2013)

[6] S. Y. Leong, D. J. Burritt, and I. Oey. Evaluation of the anthocyanin release and healthpromoting properties of Pinot Noir grape juices after pulsed electric fields. Food Chemistry 196, 833-841 (2016)

[7] R. Soliva-Fortuny, A. Blasa, D. Knorr, and O. MartinBelloso. Effects of pulsed electric fields on bioactive compounds in foods: a review. Trends in Food Science\& Technology 20, 544-556 (2009)

[8] F. J. Barba, O. Parniakov, S. A. Pereira, A. Wiktor, N. Grimi, N. Boussetta, J. A. Saraiva, J. Raso, O. Martin-Belloso, D. Witrowa-Rajchert. Current applications and new opportunities fort he use of 
pulsed electric fields in food science and industry. Food Research International 77, 773-798 (2015)

[9] Q.-X. Ou, M. Nikolic-Jaric, and M. Gänzle. Mechanisms of inactivation of Candida humilis and Saccharomyces cerevisiae by pulsed electric fields. Bioelectrochemistry 115, 47-55 (2017)

[10] A. G. Pakhomov, D. Miklavčič, \& M. S. Markov, Advanced electroporation techniques in biology and medicine. Boca Raton: CRC Press (2010)

[11] M. Rebersek and D. Miklavčič. Concepts of electroporation pulse generation and overview of electric pulse generators for cell and tissue electroporation. Advanced electroporation techniques in biology and medicine. 323-339 (CRC Press, Boca Raton, 2010)

[12] R. V. Davalos, I. L. M. Mir, B. Rubinsky. Tissue ablation with irreversible electroporation. Ann Biomed Eng. 33, 223-231 (2005)

[13] P. Y. Phoon, F. G. Galindo, A. Vicente, P. Deimek. Pulsed electric field in combination with vacuum impregnation with trehalose improves the freezing tolerance of spinach leaves. J Food Eng. 88, 144-148 (2008)

[14] E. Puertolas, N. Lopez, S. Condon, J. Raso, and I. Alvarez. Pulsed electric fields inactivation of wine spoilage yeast and bacteria. International Journal of Food Microbiology 130, 49-55 (2009)

[15] E. J. Bartowsky. Bacterial spoilage of wine and approaches to minimize it. Lett Appl Microbial 48(2), 149-156 (2009)

[16] S. Gergely, E. Bekassy-Molnar, and G. Vatai. The use of multiobjective optimization to improve wine filtration. Journal of Food Engineering 58, 311-316 (2003)

[17] C. Delsart, N. Grimi, N. Boussetta, C. M. Sertier, R. Ghidossi, M. M. Peuchot, and E. Vorobiev. Comparison of the effect of pulsed electric field or high voltage electrical discharge for the control of sweet white must fermentation process with the conventional addition of sulfur dioxide. Food Research International 77, 718-724 (2015)

[18] E.G. Alegría, I. López, J.I. Ruiz, J. Sáenz, E. Fernández, M. Zarazaga, M. Dizy, C. Torres, F. RuizLarrea High tolerance of wild Lactobacillus plantarum and Oenococcus oeni strains to lyophilisation and stress environmental conditions of acid $\mathrm{pH}$ and ethanol. FEMS Microbiology Letters 230, 53-61 (2004)

[19] L. Gonzales-Arenzana, J. Portu, R. Lopez, P. Santamaria, T. Garde-Cerdan, and I. Lopez-Alfaro. Inactivation of wine-associated microbiota by continuous pulsed electric field treatments. Innovative Food Science and Emerging Technologies 29, 187-192 (2015)

[20] E. Puértolas, G. Saldaña, S. Condón, I. Álvarez, and J. Raso. Evolution of polyphenolic compounds in red wine from Cabernet Sauvignon grapes processed by pulsed electric fields during aging in bottle. Food Chemistry 119, 1063-1070 (2010)

[21] S. Toepfl, V. Heinz, and D. Knorr. High intensity pulsed electric fields applied for food preservation. Chemical Engineering and Processing 46, 537-546 (2007)
[22] V. Heinz, and D. Knorr. Effect of $\mathrm{pH}$, ethanol addition and high hydrostatic pressure on the inactivation of Bacillus subtilis by pulsed electric fields. Innovative Food Science \& Emerging Technologies 1(2), 151-159 (2000)

[23] A. H. El-Hag, S. H. Jayaram, O. R. Gonzales, and M. W. Griffiths. The influence of size and shape of microorganism on pulsed electric field inactivation. IEEE Transactions on Nanobioscience 10(3), 133-138 (2011)

[24] J. R. Mattar, M. F. Turk, M. Nonus, and N. I. Lebovka. S. cerevisiae fermetation activity after moderate pulsed electric field pre-treatments. Bioelectrochemistry 103, 92-97 (2015)

[25] T. Tanino, S. Sato, M. Ohshima. Analysis of the stress response of yeast Saccharomyces cerevisae toward pulsed electric field. J. Electrost. 70, 212-216 (2012)

[26] R. S. Jackson, Chem. Cons. of Gr. and Wine. Wine Science-Third Edition 270-331 (San Diego: Academic Press, 2008)

[27] R. B. Boulton, The copigmentation of anthocyanins and its role in the colour of red wine: a critical review. American Journal of Enology and Viticulture 55, 67-87 (2001)

[28] S. Vidal, L. Francis, A. Noble, M. Kwiatkowski, V. Cheynier \& E. Waters. Taste and mouthfeel properties of different types of tannin-like polyphenolic compounds and anthocyanins in wine. Analytica Chimica Acta 513, 57-65 (2004)

[29] M. Sack, C. Eing, R. Stängle, A. Wolf, G. Müller, J. Sigler, L. Stukenbrock: "Electric Measurement of the Electroporation Efficiency of Mash from Wine Grapes", Trans. DEI 16(5), 1329-1337 (2009)

[30] M. Sack, J. Sigler, C. Eing, L. Stukenbrock, R. Stängle, A. Wolf, and G. Müller. Operation of an Electroporation Device for Grape Mash IEEE Transactions on Plasma Science 38(8), 1928-1934 (2010)

[31] M. Corrales, S. Toepfl, P. Butz, D. Knorr, \& B. Tauscher. Extraction of anthocyanins from grape byproducts assisted by ultrasonics, high hydrostatic pressure or pulsed electric fields: a comparison. Innovative Food Science and Emerging Technologies 9, 85-91 (2008)

[32] N. Boussetta, N. Lebovka, E. Vorobiev, H. Adenier, C. Bedel- Cloutour, \& J. L. Lanoisellé. Electrically assisted extraction of soluble matter from Chardonnay grape skins for polyphenol recovery. Journal of Agricultural and Food Chemistry 57, 1491-1497 (2009)

[33] N. El Darra, H. N. Rajha, M.-A. Ducasse, M. F. Turk N. Grimi, R. G. Maroun, N. Louka, and E. Vorobiev. Effect of pulsed electric field treatment during cold maceration and alcoholic fermentation on major red wine qualitative and quantitative parameters. Food Chemistry 213, 352-360 (2016)

[34] A. Angersbach, V. Heinz, and D. Knorr. Effects of pulsed electric fields on cell membranes in real food systems. Innovative Food Science and Emerging Technologies 1, 135-149 (2000) 